give an overview of a proposed NATO study of this issue, and to invite national participation for the attendees.

The aims of this study will be:

a. To demonstrate that formatted email with attached images, sent to an internet server, is a valid means of interoperable teleconsultation in a multinational operational environment.

b. To determine the concordance and clinical relevance of specialist opinions between specialists from different countries in:

i. Diagnosis;

ii. Proposed treatment modalities; and

iii. Proposed patient disposition.

c. To demonstrate that clinical advice from another nation is acceptable to, and usable by, a field medical unit.

The proposed technical implementation of this study will be reported, with details as to the desired participation on the part of nations.

Keywords: advice, clinical; diagnosis; disposition; e-mail; field medical unit; military; operation; relevance; support, medical; teleconsultation; treatment

Prehosp Disast Med 2003;18(s1)s30.

\section{Vision for Coalition Health Service Support, 2020 Time Frame}

\section{Jeff Drifmeyer}

Senior Military Analyst, SY Coleman Research Corp., Colorado Springs, Colorado, USA

This concept paper proposes future, fully networked, coalition medical support of the North Atlantic Treaty Organization (NATO) operations. By the 2020 time frame, the military health systems of the expanded NATO member states will have been transformed. Fully integrated, coherent coalition capabilities will provide quality medical care across the range of NATO operations, from conflict to humanitarian relief. Through shared research and development, integrated cross-training, and coordinated combat developments (from concepts to force structure), dedicated, highly skilled providers of all of the member states will integrate their activities collaboratively. This will markedly improve both effectiveness and efficiency. Ideas, prototypes, and solutions will derive from, and will be shared among, all members and multiple industries and fields (logistics, healthcare, information science, communications, etc.). The transformed NATO health system will enhance force health protection for all, reduce logistics requirements, and enable improved NATO operational capabilities. Specifically, the historic perspective in which medical matters within NATO were regarded strictly as a national responsibility will have been changed. By 2020, medical operations will be fully inter-operable, with medical personnel regularly training and deploying on the basis of requirements and capabilities, not nationality.

In addition to new concepts and doctrine, new technologies will fundamentally change NATO medical operations. Casualty rates can become the lowest in history with the use of synthetic blood and fibrin bandages significantly reducing trauma fatalities. With secure signaling devices, calls for "Medic!" will be nearly automatic, and "friendly fire" casualties will no longer be a problem. The next generation of personal protective devices will prevent or reduce the severity of wounds, while agent detectors and alarms will be individual, not area-based. Hands-free satellite phones and tele-medicine will connect deployed medical personnel with major trauma centers in every NATO member state. Response capabilities will rapidly sense and respond to movement and treatment requirements. Patients will no longer be "held" at staging facilities, and patient evacuation, both tactical and strategic, will be fully integrated. Medical care will be provided by a NATO coalition force, not a service or national responsibility.

Keywords: 2020; battlefield medicine; casualties, rates of; coalition; concept; doctrine; future; integration; medical care; military medicine; NATO; responses; technologies; telemedicine Prehosp Disast Med 2003:18:s(1)s30.

E-mail: jeff.drifmeyer@je.jfcom.mil

\section{The Swedish National Air Medevac (SNAM) \\ Hakan Osterhed}

Head of Emergency Planning and Security, Swedish Civil

Aviation Administration

The purpose of the project is to transform the present Scandinavian Airlines (SAS) organization for national crisis and war into a modern air ambulance organization. It will be able to tender and care for 35 patients in one aircraft, any Boeing 737-800 in the SAS fleet, with six patients in intensive care and another six on stretchers. The organization will be used not only in wartime, but also when society is under heavy stress and the normal resources are not sufficient. It also can be used for international humanitarian missions, and will be mission-ready from Stockholm-Arlanda within six hours after a call is received.

A general demand for maximum utility flexibility, the SAS Boeing 737-800 fleet will not need any prior technical modifications. The intensive care unit, the MICU, will be portable and mobile with a maximum weight not to exceed $70 \mathrm{~kg}$. It will be self-contained with power for four hours, and also will contain 1,800 liters of oxygen, a ventilator, a supervision monitor, syringe-and volume infusion pumps, a defibrillator, suction, and blood gas and blood chemistry analysis. The unit will also meet all formal authority demands concerning flight and patient safety.

The MICU will also be adaptable to Swedish road ambulances, smaller air ambulances, and Medevac helicopters used in Sweden.

There will be four medical crews available: Each crew consists of six doctors, 11 nurses, and a medical technician, all specially trained in flight medicine. The project was launched in 2001, and will have the transformed organization operative by the end of 2004 .

Keywords: air ambulance; crisis; equipment; helicopters; medevac; mobile intensive care units; staff; Sweden; war

Prebosp Disast Med 2003:18:s(1)s30

E-mail: hakan.osterhed@lfv.se 